\title{
Enhancing Physical Learning Environment for Autism
}

\section{Roslinda Ghazali, Siti Rasidah Md. Sakip2,4, Ismail Samsuddin ${ }^{3}$}

1 Department of Post-graduate, ${ }^{2}$ Department of Landscape Architecture, ${ }^{3}$ Department of Architecture, Faculty of Architecture, Planning \& Surveying, Universiti Teknologi MARA Perak Branch, Seri Iskandar Campus, Perak, Malaysia.

${ }^{4}$ Green Safe Cities Research Group, Universiti Teknologi MARA, Shah Alam Campus, Selangor, Malaysia.

lindakeruing@gmail.com, sitir704@uitm.edu.my, ismai578@uitm.edu.my

\begin{abstract}
The designated learning environment for autism is unique and should consider sensory issues to overcome their needs. The purpose of this paper is to review related articles to gain a better understanding of autism needs regarding sensory design, sensory issues, sensory space, internal environment, and physical learning environment. This paper will outline the sensory design of the physical learning environment that would impact the sensory design towards the physical learning environment. This research paper concludes to be a guide for the designer to overcome sensory input so that autistic can learn more efficiently and develop with less stress.
\end{abstract}

Keywords: Autism; sensory design; sensory issues; physical learning environment

eISSN: 2398-4295 @ 2019. The Authors. Published for AMER, ABRA \& cE-Bs by e-International Publishing House, Ltd., UK. This is an open access article under the CC BY-NC-ND license (http://creativecommons.org/licenses/bync-nd/4.0/). Peer-review under responsibility of AMER (Association of Malaysian Environment-Behaviour Researchers), ABRA (Association of Behavioural Researchers on Asians) and CE-Bs (Centre for EnvironmentBehaviour Studies), Faculty of Architecture, Planning \& Surveying, Universiti Teknologi MARA, Malaysia.

DOI: http://dx.doi.org/10.21834/ajbes.v4i17.180 


\subsection{Introduction}

Autism is a disorder of social development, language, and communication. They are having inappropriate behaviours, attention and varies in symptoms. One of the many autistic characteristics is that children with autism isolate themselves and show less attention to their environments (Noiprawat \& Sahachaiseri, 2010). Autistic also confront their problems in sensory processing and sensory integration which negatively impact their engagement in daily activities (Matin et al., 2017). Every autistic child is having different academic problems, such as difficulties in class participation, low attention span, and inappropriate behaviors which hinder their ability to take part in educational activities. Matin et al. (2017) also mentioned that autistic children are distracted easily from education by their own repetitive, restless, and disruptive classroom behaviors. The conducive learning environment can attract and stimulate their interest when they participate in skill-enhancing activities and promoting the development of autistic children (Noiprawat \& Sahachaiseri, 2010). Therefore, Noiprawat \& Sahachaiseri suggested that creating an appropriate environment would enhance and develop their behaviours, emotion and society will accommodate autistic children to live their lives like normal children. Not only that, autistic children usually experience disappointment in educational progress, as such the usual intervention strategies, since these strategies do not deal with the sensory issues that may reduce the distressing behavior. Hence, Matin et al., (2017) stressed that ignoring proper changes in the environment may have severe negative impacts on the learning processes of autistic children. The designated learning environment should consider the sensory issues to overcome their needs as they are a unique person. However, designers are lack of experience regarding sensory design while designing learning spaces for autistic children (Mcnally, Morris, \& Mcallister, 2013). They need to have a better understanding of autism and how it may affect learning among autism. They also need help putting appropriate strategies in place to deal with sensory issues that impact autistic children. This paper would review related articles to gain a better understanding of autism needs in terms of sensory design, sensory issues, sensory space, internal environment, and physical learning environment. Generally, Henshall (2008) explained that sensitivity to sensory stimuli occurs along a variety, from hypersensitive to hyposensitive responsiveness.

Researcher elaborates the impact on design towards the seven sensory systems which are within the nervous system for examples sound, touch, vision, taste, smell, movement, and body position. Once autistic children are starting their learning process, the quality of the environment is so much important and avoid confusing and frustrating to the autistic mind (Beaver, 2006). The autism is an extremely complex condition which affects each person differently and can benefit more from the sensory input that the built environment provides (The National Autistic Society, 2015). ASD also often engage in problematic behaviors such as aggression, self-injurious behavior, and stereotyped behaviors, as they easily disrupt the learning environment. Furthermore, this situation would make other children at risk and making it very difficult for them to transition and access mainstream education settings. The objective of this paper is to determine how autistic would impact by the sensory design towards the physical learning environment.

It is important to create a learning environment that accommodates the different needs 
of the autistic child and takes into account on how to deal with behavioral and influence their success through alteration and treatment of their physical environments (Purple Cherry, Ap, \& Underwood, n.d.). The strategy for the research design was a case study that involved an early intervention center facilitated by the government. This intervention center is a benchmark and located in a non-urban area. The methodology for data collection involved Design Criteria Checklist, personal on-site observation, and photograph. The findings revealed that the Design Criteria Checklist would help the designer with the basic in mind to minimize the sensory issues. Therefore, the design criteria checklist would be a guide for a designer to overcome sensory input. Hence, it would overwhelm autistic children so that they can learn more efficiently and develop with less stress.

\subsection{Literature Review}

Researchers elaborated about ASD and highlighted the impact of sensory design on autistic behaviour in this section. This section reviewed related articles to gain a better understanding of autism needs, physical learning environment and specifically on sensory design.

\subsection{Type of ASD}

Children with ASD have a developmental disability that can create social, communication, behavioral challenges, a variety of disabilities and impairments, and each child is affected differently (Schaffhauser, 2018). ASD includes Classic Autism, Pervasive Developmental Disorder (PDD), Asperger's syndrome (AS), Rett's syndrome, and Childhood Disintegrative Disorder (Reynolds, 2015; Rudy, 2017). ASD occurs among males at four times more than females and involves moderate to severe impairments in communication, socialization, and behavior (Raar, 2012).

\subsection{ASD and Sensory Processing}

Researchers have widely recognized that people with ASD have unusual sensory experiences (Henshall, 2008). Sensory processing is referring to the nervous system in which the brain has trouble receiving and responding to the information that comes in through the senses (Henshall, 2008; Phillips et al., 2011). For example, some children may overreact to environmental stimuli such as traffic noise, an airplane overhead, or even sunlight, while others may fail to notice or respond to this type of input (Autism Research Institute, 2014). Autistic children may process information from their senses differently and unable to filter out irrelevant noises or sights such as a microwave whirr or flickering light (Sarris, 2016). Saris also explained that certain sounds, lights, or textures to be severely distracting or uncomfortable and with those sensory problems it would trigger for other behaviors often found in autism, such as extremely picky eating habits or even wandering. Henshall (2008) mentioned that these individuals might actively seek out or avoid sensory information, for example by putting their hands over their ears to block out sounds. Besides, children may have difficulties and engaging with others because of atypical sensory responses. As a matter of facts, Phillips et al. (2011) also mentioned that behavioral and emotional problems were associated with sensory processing differences and sensory symptoms were 
significantly related to stereotyped interests and repetitive behaviors in ASD. Specifically, Henshall (2008) explained that sensitivity to sensory stimuli occurs along a variety, from hypersensitive to hyposensitive responsiveness. Hyper-responsiveness refers to the sensory channel being too 'open', and so there is too much stimulation for the brain to cope with, whereas hypo-responsiveness refers to the sensory channel not being open enough; therefore too little of the stimulation can get in, and the brain is deprived of sensory input (Henshall, 2008) (Phillips et al., 2011). In Table 1, the researcher summaries the seven sensory systems and their functions which are within the nervous system: sound, touch, vision, taste, smell, movement, and body position.

Table 1. The Seven Sensory Systems

\begin{tabular}{ll}
\hline Vision & The faculty of seeing. \\
\hline Hearing & The faculty of perceiving sound. \\
\hline Vestibular system & $\begin{array}{l}\text { Refers to structures within the inner ear that detect movement } \\
\text { and changes in the position of the head. }\end{array}$ \\
\hline $\begin{array}{l}\text { Vestibular system } \\
\text { Olfaction (the sense of smell) }\end{array}$ & Perceiving odors or scents. \\
\hline Gustation (the sense of taste) & $\begin{array}{l}\text { Perceiving the sensation of a soluble feeling caused in the mouth } \\
\text { and throat by contact with that substance. }\end{array}$ \\
\hline Tactile system & Perceiving touch, pressure, pain, temperature. \\
\hline Proprioceptive system & $\begin{array}{l}\text { Perceiving stimuli produced within an organism, especially } \\
\text { relating to the position and movement to the body. }\end{array}$ \\
\hline
\end{tabular}

(Source: Henshall, 2008)

\subsection{Sensory Sensitivity (SS)}

Researchers elaborated about sensory sensitivity that occurs a variety from high stimulation and low stimulation responsiveness.

\subsubsection{Sensory Sensitivity of High Stimulation (Hypersensitive)}

Hypersensitive means were over-responsive to sensory stimuli. Children with hypersensitive can be easily overwhelmed with the environment that terrifying at times. Such as loud or sudden noises that would make them feel physically painful (Gaines, Bourne, Pearson, \& Kleibrink, 2016). Some experts believe that this kind of sensory overload is experienced more among individuals with Asperger's syndrome than other individuals on the spectrum (Gaines et al., 2016). Table 2 shows the list of children with ASD appear to exhibit auditory and tactile processing difficulties the most.

\subsubsection{Sensory Sensitivity of Low Stimulation (Hyposensitive)}

Hyposensitive means under-responsive as if certain sensory information goes unnoticed or certain senses are impaired (Gaines et al., 2016). Children who were diagnosed had hyposensitive with auditory tendencies were often thought to be deaf. Hyposensitive are often qualified as "sensory-seeking," meaning they often create or generate their own sensory experiences either for pleasure or to block out other unpleasant stimuli (Gaines et al., 2016). Table 2 shows the list of children with ASD appear to exhibit auditory and tactile processing difficulties the most. 
Table 2. Hypersensitive and Hyposensitive Symptoms of ASD

\begin{tabular}{|c|c|c|}
\hline Sense & Hyposensitive & Hypersensitive \\
\hline Auditory (Sound) & $\begin{array}{l}\text { Does not respond when the name } \\
\text { called; Enjoys strange noises; } \\
\text { Enjoys making loud, excessive } \\
\text { noises }\end{array}$ & $\begin{array}{l}\text { Overly sensitive to loud noises; } \\
\text { Appears to hear noises before } \\
\text { others; Cannot function well with } \\
\text { background noise } \\
\text { Avoids }\end{array}$ \\
\hline Tactile (Touch) & $\begin{array}{l}\text { Touches people and objects } \\
\text { unnecessarily; Has abnormally } \\
\text { high pain threshold (does not } \\
\text { appear to be hurt after a hard fall); } \\
\text { Does not seem to feel extreme } \\
\text { temperatures }\end{array}$ & $\begin{array}{l}\text { Avoids wearing certain fabrics; } \\
\text { Becomes distressed during } \\
\text { grooming; Does not like being wet } \\
\text { or going barefoot; Reacts } \\
\text { negatively to being touched }\end{array}$ \\
\hline Visual (Sight) & $\begin{array}{l}\text { Disregards people or objects in } \\
\text { the environment; Can see only } \\
\text { outlines of certain objects; Likes } \\
\text { bright colors and bright sunlight } \\
\text { Moves }\end{array}$ & $\begin{array}{l}\text { Bothered by bright lights (covers } \\
\text { eyes or squints); Easily distracted } \\
\text { by movement; Stares at certain } \\
\text { people or objects }\end{array}$ \\
\hline Vestibular (Motion) Smell/Taste & $\begin{array}{l}\text { Moves around unnecessarily; } \\
\text { Enjoys spinning in circles; } \\
\text { Becomes excited about any task } \\
\text { involving movement }\end{array}$ & $\begin{array}{l}\text { Seems unbalanced; Becomes } \\
\text { distressed when upside-down or } \\
\text { when feet leave the ground }\end{array}$ \\
\hline Smell/Taste (Olfactory) & $\begin{array}{l}\text { Some reports of Pica or eating } \\
\text { non-food substances; "Feels" } \\
\text { objects with the mouth; Seeks out } \\
\text { strong smells; Oblivious to some } \\
\text { scents }\end{array}$ & $\begin{array}{l}\text { Picky eater; Will only eat foods } \\
\text { with certain textures, with } \\
\text { particular smells, or at a certain } \\
\text { temperature }\end{array}$ \\
\hline $\begin{array}{l}\text { Proprioception (Sense of } \\
\text { body's location) }\end{array}$ & $\begin{array}{l}\text { Unaware of body position in } \\
\text { space and body sensations like }\end{array}$ & $\begin{array}{l}\text { Odd bodily posture; } \\
\text { Uncomfortable in most situations; }\end{array}$ \\
\hline Unaware & $\begin{array}{l}\text { hunger; } \\
\text { Often lean against people or } \\
\text { objects }\end{array}$ & $\begin{array}{l}\text { Difficulty manipulating small } \\
\text { objects }\end{array}$ \\
\hline & (Source: K. Gaines et al., 2016) & \\
\hline
\end{tabular}

\subsection{Physical Learning Environment (PLE)}

The learning environment refers to the space allocated for classrooms, science labs, open areas and offices (Amirul, Che Ahmad, Yahya, Lee Abdullah, Adnan and Mohamed Noh, 2013). They defined the learning environment as the social context, psychological and pedagogical, which can affect learning, achievement, and attitudes of the students. Research done by Ahmad, Shaari, Hashim, \& Kariminia (2015) defined the physical environment as human comfort, quality of furnishing and finishing, spatial planning and design, air quality and noise or pollution and spatial arrangement shown to affect child's play behaviour, influencing their learning, promote better education and positive behaviours among the children. They mentioned that all these are technical architectural features that can be modified to suit a child's development better. The learning environment in this context comprises of the social environment (the students, the teachers, and the curriculums or programs) and the physical environment (building and infrastructure) (Shaari \& Ahmad, 2016). Learning environment and features that are in it played a significant role in improving learning in schools and identified as significant determinants of student learning. Learning environment capable of stimulating 
students to engage in the learning process and be able to influence the behavior of students as well as to assist in the development of their skills or cognitive perception. Stimuli from school environments influence children physical, cognitive, social and emotional development and learning (Shaari \& Ahmad, 2016).

\subsection{Sensory Design (SD)}

The environment gives a huge impact on a child with Sensory Sensitivity; also known as Sensory Processing Disorder or Sensory Integration Difficulty. Their senses can be either over-developed (hypersensitive) or under-developed (hyposensitive) which can result in feelings of anxiety, stress \& occasionally, physical pain. Both can have an impact on how a child handles different environments (Barker, 2014). The sensory design is design for living which how space feels, sounds, looks, smells, and functions can be incredibly affecting one or more of the seven senses which can have an overwhelming effect on their life (Society, 2015). When designing areas for children on the autism spectrum, it is important to have knowledge and understanding of how they experience the environment because it is also important to know that not all children are affected in the same way or to the same range. Whereas many children are capable of learning within mainstream environments, some children require a more adapted and unique setting (Scott, 2009). The Autism ASPECTSS ${ }^{\mathrm{TM}}$ Design Index was developed by Mostafa (2015) specifically is based on the Sensory Design Theory, which by altering the sensory environment using specific design interventions. The index summarizes the seven design criteria conclusively recommended to facilitate and improve the user-built environment relationship for autistic individuals are acoustics, spatial sequencing, escape space, compartmentalization, transition spaces, sensory zoning, and safety.

\subsection{Methodology}

This study had utilized a qualitative methodology which used a single case study. The aim of this research was to collect a description of the strategy used by governmental organizations in dealing with autistic children with special emphasis on early intervention. The data collections involve at least three methods for triangulation - Design Criteria Checklists (DCC), personal on-site observation and photograph documentation.

\subsection{Procedure}

Prior to the site visits, consents were first obtained from the Director of Autism Center. Preceded by initial briefings about the setup of the center, the representatives accompanied the site visits and responded to spontaneous general inquiries about the physical environment of the Autism Center. Data collected involved personal observations made with notations and photographic documentations about the facilities provided and on the overall ambiance. The Design Criteria Checklist were then filled. Visits to the Autism Centre were done once and lasted about 4 hours. 


\subsection{Instrument}

Before visiting the site, the researcher had prepared DCC that was based on a literature study and reviewed research done by McNally et al. (2013). The theoretical research helped to develop variables and DCC for field study. The outlines of DCC developed which has elaborated on the autistic environment. DCC is part of benchmarking tool assisted in identifying the design criteria in the autism center. It identified a design through a series of statements, which encompassed the four areas - Physical Learning Environment (PLE), Internal Environment (IE), Sensory Issues (SI) and Sensory Spaces (SS).

\subsection{Site Setting}

The study took place at Autism Center for students with severe communication disorders, including students diagnosed with autism. It is a pioneer autism center in Malaysia and become a benchmark and the setting for the study located at the non-urban area. The study involves children at the age of four to six years old and the autism center facilitated by the government. Each learning classroom accommodates a maximum of eight students and two interventionists. This is a guideline set by the Economic Planning Unit (EPU) under the Special Education Program.

\subsection{Results and Discussion}

The study conducted by observing the autistic environments in the autism center. Based on the visit, the data collected from observation and notes of autistic environment DCC. The overall result of the study highlighted the criteria that relate to Physical Learning Environment (PLE), Internal Environment (IE), Sensory Issues (SI) and Sensory Spaces (SS).

\subsection{Physical Learning Environment (PLE)}

The selected case study designed with two storey height. The larger schools can be disorientating and frightening places for autistic children. ASD children would be more tolerable and hopefully even enjoyable when their arrival at school. The building entrance designed as straightforward, welcome and stress-free for them; however the autism center has double volumn spaces provided at drop off area. The building scale with a large school can be daunting for a pupil with autism; however for this center it is designed with two storey height institutional building. This small institutional building with simple organizational layouts offers the most basic conditions for easy comprehension among autistic. Regarding safety and security, access to and from the school is secure, and the children were monitored at all times. 


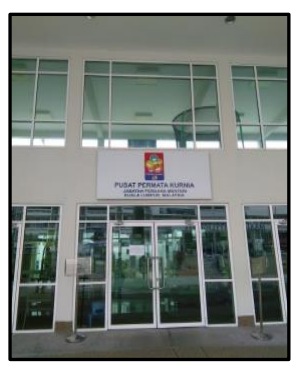

Figure 1: The Entrance (Source: Author)

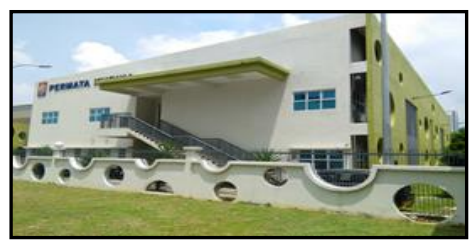

Figure 2: The Scale (Source: Author)

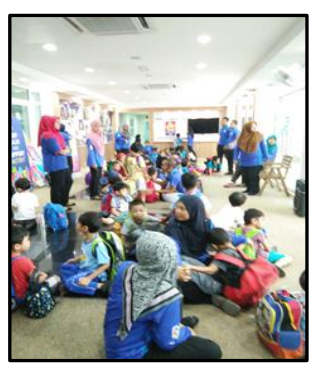

Figure 3: Safety \& Security (Source: Author)

\subsection{Internal Environment (IE)}

The internal environment has been designed to comprehend the ASD child impairment. Children with ASD often need more personal space due to their proprioception problem and in processing information.

They can find it more challenging to locate themselves in space. In this autism center, the designer has to allow extra space for circulation, especially at corridors and classrooms for their personal space and movement. It is essential to avoid long corridors, complex layout and frequent changes of level and researcher found that the wayfinding around the school is as clear and comprehensible for the children.

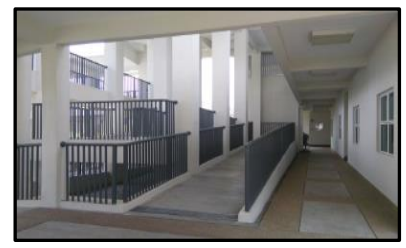

Figure 4: Space and movement (Source: Author)

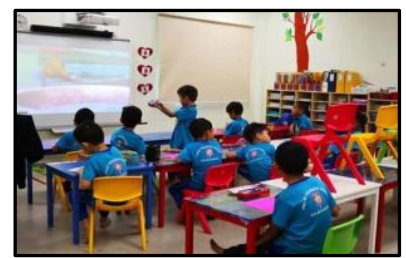

Figure 6: Classroom (Source: Author)

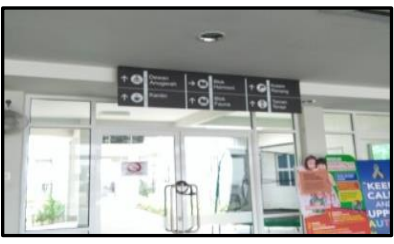

Figure 5: Wayfinding (Source: Author)

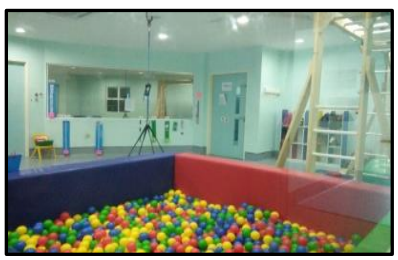

Figure 7: Activity room

(Source: Author) 
Equally important, the legibility of space helps them to orientate themselves and identify the activities associated with various rooms. The researcher found that visual clues provided at each room with its own personalizing using individual colors or objects to facilitate autistic children accessing the environment. Furthermore, transition space, for example from classroom to other classrooms, autistic is having difficulty in preparing themselves to change the environment. Therefore, the threshold is important for them to give afforded time and space to prepare for this change. From researchers observation, there is a seated space within the classroom or in the form of a recess in a corridor provided for them to coping the situation. Apart from that, the classroom is the most important to autistic children.

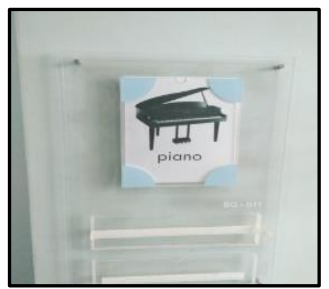

Figure 8: Legibility (Source: Author)

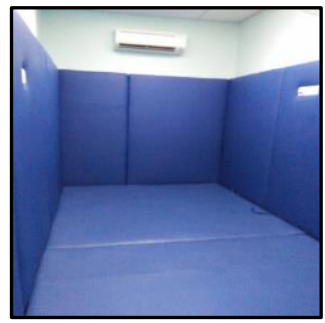

Figure 10: Quiet room (Source: Author)

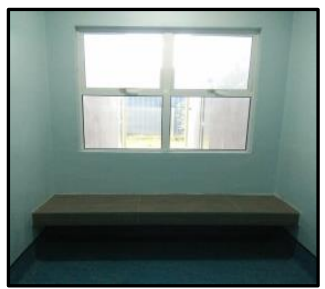

Figure 9: Threshold (Source: Author)

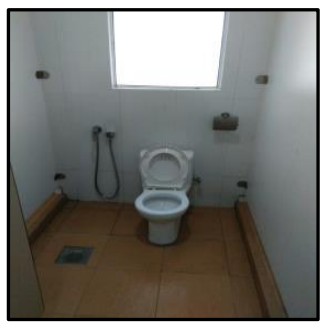

Figure 11: Toilet

(Source: Author)

The autistic classroom should feel comfortable, relaxed, a safe place from the chaos and a place of security and familiarity. Before this, researchers found that the choice of colors, textures, and materials are carefully selected physiologically, psychologically and therapeutically. The classroom painted in light blue color and off-white color which considered as neutral and calming colors for the ASD. As for the activity room, it painted in bright blue color which considers as neutral and calming colors for the ASD. Not only have that, but the equipment is also secured for autistic to use during their activity playtime. Conversely, the quiet room is a space provided at nearby the classroom to allow the child to calm down. The room furnished with a padded wall to avoid the children form injured during their tantrum and also was painted in a light blue color to bring the calm ambiance in the room. Lastly, the toilet and pantries provided at each classroom as part of a toilet training program and also 
the living skill program. They provide the showers \& pantries in ergonomic and smell free for autistic children.

\subsection{Sensory Issues.}

ASD may experience sensory integration problem to one or any of the seven senses. The designer should consider the sensory issues that would trigger and likely upset the children.

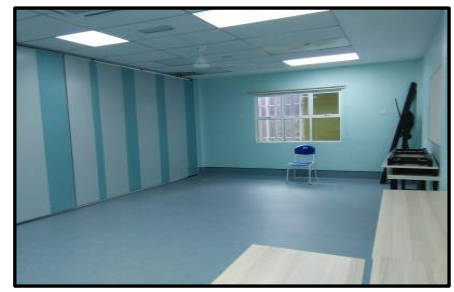

Figure 12: Visual distraction

(Source: Author)

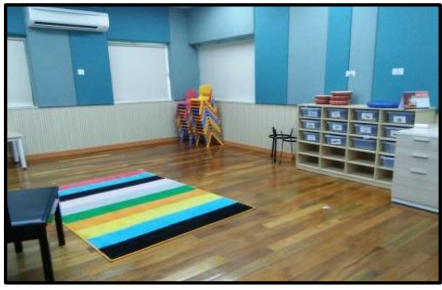

Figure 13: Sun and glare

(Source: Author)

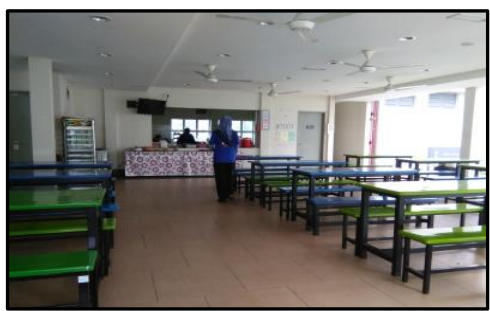

Figure 14: Smell

(Source: Author)

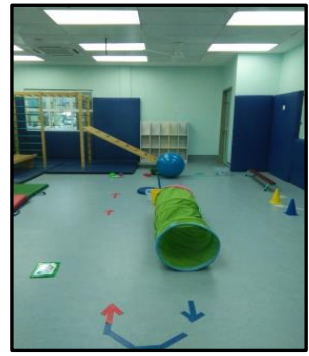

Figure 15: Lighting (Source: Author)

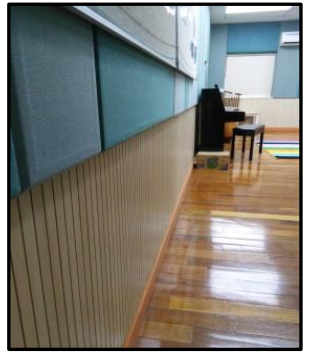

Figure 16: Acoustic (Source: Author) 
The autism center has considered the sensory issues especially on visual distraction where the choice of colors, textures, and materials are carefully selected physiologically, psychologically and therapeutically. From the observation the classroom was painted in light blue colour and off-white color which consider as neutral and calming colors for the ASD. Not only that, sun and glare would be the most potentials would triggers and problems to autistic children. However, in the autism center the provision of windows the blinds provided to minimize distraction. The flicker of fluorescent lighting can be disruptive to autistic, and researchers found that the lighting has been taken care in choosing artificial lighting. Too much noise from places such as playgrounds, sports facilities, dining rooms, and plant rooms can be distracting and troublesome to autistic children. However, researchers found that the acoustics matter has been taken care of choosing the right materials and acoustic panel provided at music room \& assembly hall. Strong and bad smells even subtle odors are potentially distracting to autistic children. The autism center has allocated the school kitchen, dining and swimming pool away from the learning area to avoid such smells and odors

\subsection{Sensory Design.}

Autistic children struggle with visual distraction; calm, low stimulus space would be an ultimate learning environment for most of them.

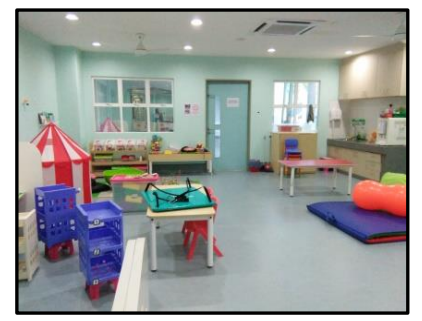

Figure 17: Calm, low stimulus space (Source: Author)

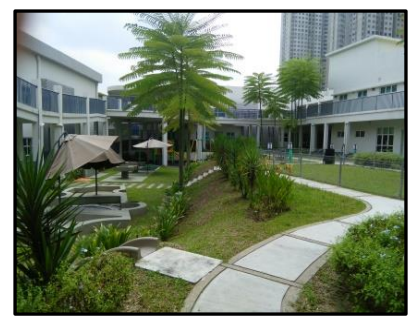

Figure 18: Sensory garden (Source: Author)

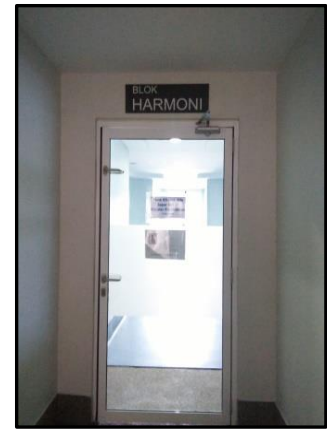

Figure 19: Safety \& security (Source: Author)

It is essential to determine what and how much to display on the wall. The researcher found that the interventionist has been taken care of by choosing colors for materials of storage, teaching materials, etc. The wall was painted in a light blue colour and also the selection of floor material such as non-slip vinyl in light blue color which considers as neutral and calming colors for the classroom. Safety and security is the ultimate importance due to autistic children having difficulty to understand the dangers in the environment. They also attempt to escape from the classroom or injuring themselves. However, the autism center has considered regarding safety and security. Especially the doors provided double locks and the grille design in vertical to avoid them to climb. Autistic children responded positively in the garden. Natural environment may promote social interaction and improvement in autism symptoms (Sachs \& Vincenta, 2011). From researcher's observation, this autism center 
provides a sensory garden with inclusive nature-based and fun places for all children to play and explore.

\subsection{Conclusion}

It is important to consider that those elements discussed such as the building entrance, building scale, safety and security, personal space and movement, wayfinding, legibility, threshold, classroom, activity room, quiet room, toilet, visual distraction, sun and glare, lighting, acoustic, smell, calm, low stimulus space, and sensory garden during creating learning environment. As discussed by Mcnally et al. (2013), if considered the surrounding environment appropriately it could enhance the learning experience and positively influence the child's development. Our observation on the autistic environments in the autism center showed that the basic needs have been considered and are important in designing a physical learning environment. It is hoped that by creating a conducive learning environment not only optimizes the classroom environment but also upon a parent's and teacher's satisfaction and the most significant is to create a conducive environment that impacts the body, behaviour, and response to an environment. Perhaps architects and designers could create an appropriate environment to enhance and develop autistic behaviors, emotional and would accommodate autistic children to live their lives like normal children. To enhance the conducive physical learning environment, designers should address to understand an environment and to reduce the symptoms. Hence, this research could contribute to the creation of a quality environment for autistic children within the Malaysian context.

\subsection{Recommendations}

It is proposed that future research may present sensory design, sensory issues, sensory space, internal environment, and physical learning environment versions where the criteria are weighted. This can be based on a survey of parents, teachers, caregivers, therapists and individuals related with autism to determine the relative importance to autism environment. Apart from that, the other components such as furniture, color, detailing and material should be included in the design criteria for autism and this is to provide an enriching autism environment to support and encourage spiritually, emotionally, physically and mentally.

\section{Acknowledgment}

I would like to thank my supervisor Dr. Siti Rasidah Md Sakip and Asso. Prof. Dr. Ismail Samsuddin for supporting me. Also, I would thank Jabatan Kerja Raya Malaysia for allowing me to further my study. 


\section{References}

Ahmad, S. S., Shaari, M. F., Hashim, R., \& Kariminia, S. (2015). Conducive Attributes of Physical Learning. The environment at Preschool Level for Slow Learners. Procedia - Social and Behavioral Sciences, 201(February), 110-120. https://doi.org/10.1016/j.sbspro.2015.08.138

Amirul, N. J., Nidzam, C., Ahmad, C., Yahya, A., Faizal, M., Abdullah, N. L., ... Noh, N. M. (2013). The physical the classroom learning environment, (2nd International Higher Education Teaching and Learning Conference 2013), 9 pages.

Autism Research Institute. (2014). Autism-Friendly Design Ideas. The Children's Hospital of Philadelphia, 2. Retrieved from https://www.carautismroadmap.org/autism-friendly-design-ideas/

Barker, K. (2014). Sensory Design For Autism. Retrieved December 18, 2017, from http://justlivinginteriors.co.uk/sensory-design-autism/

Beaver, C. (2006). Designing Environments for Children \& Adults with ASD. Autism Safari 2006 2nd World Autism Congress \& Exhibition.

Gaines, K., Bourne, A., Pearson, M., \& Kleibrink, M. (2016). Designing for Autism Spectrum Disorders. New York: Routledge Taylor \& Francis Group. https://doi.org/10.4324/9781315856872

Henshall, C. (2008). Unusual sensory experiences in people on the autism spectrum. Thesis. The University of Warwick. Retrieved from http://webcat.warwick.ac.uk/record=b2247749 S1

Matin, N., Ph.D., S., Allah, H., Phd, H., Ali, S., Ph.D., S., ... Phd, H. H. A. (2017). The Impact of Dynamic Seating on Classroom Behavior of Students with Autism Spectrum Disorder. 29 Iran J Child Neurol. WINTER Iran J Child Neurol. Winter, 11(111), 29-36. Retrieved from https://www.ncbi.nlm.nih.gov/pmc/articles/PMC5329757/pdf/ijcn 11-029.pdf

Mcnally, H., Morris, D., \& Mcallister, K. (2013). Experiencing Primary School through the lens of the autistic spectrum. Aldo goes to Primary School. (D. M. \& K. M. A. Hugh McNally, Ed.). McNally Morris Architects.

Mostafa, M. (2015). An Architecture for Autism: Built Environment Performance in Accordance with the Autism ASPECTSSTM Design Index. Design Principles and Practices: An International Journal-Annual Review, 8(1), 55 71. https://doi.org/10.18848/1833-1874/CGP/v08/38300

Noiprawat, N., \& Sahachaiseri, N. (2010). The model of environments is enhancing autistic children's development. Procedia - Social and Behavioral Sciences, 5, 1257-1261. https://doi.org/10.1016/j.sbspro.2010.07.271

Phillips, J., Minjarez, M., Mercier, E., Feinstein, C., \& Hardan, A. Y. (2011). Autism spectrum disorders. Handbook of Developmental Psychiatry, 66(5), 463-490. https://doi.org/10.4324/9781315283531

Purple Cherry, C., Ap, L., \& Underwood, L. (n.d.). The Ideal Home for the Autistic Child : Physiological Rationale for Design Strategies. Autism Science Digest: The Journal of Autismone, (03), 131-138. Retrieved from www.autismone.org

Raar, E. (2012). Sensitive Design. Syracuse University.

Reynolds, J. D. (2015). A View of Parents of Children with Autism Spectrum Disorder. Liberty University.

Rudy, L. J. (2017). Is There More Than One Autism Spectrum Disorder ? Brain \& Nervous System Autism, (May 2013). Retrieved from https://www.verywellhealth.com/what-are-the-different-types-of-autism-260611 
Sachs, N., \& Vincenta, T. (2011). Outdoor Environment for Children with Autism and Special Needs. Implications InformeDesign, 09(1), 8 pages. https://doi.org/10.1038/clpt.2010.281

Sarris, M. (2016). What Do We Know about Noise Sensitivity in Autism ? Interactive Autism Network, 1-6.

Retrieved from https://iancommunity.org

Schaffhauser, D. (2018). Sensory Room Provides Focus for Autistic Students. THE Journal -Special Needs.

Retrieved from file:///C:/Users/User/Dropbox/ORGANIZER/AUTISM/sensory design/Sensory Room Provi des

The focus for Autistic Students -- THE Journal.html

Scott, I. (2009). Designing learning spaces for children on the autism spectrum. Good Autism Practices, (10)1(May 2009), 36-51.

Shaari, M. F., \& Ahmad, S. S. (2016). Physical Learning Environment: Impact on Children School Readiness in Malaysian Preschools. Procedia - Social and Behavioral Sciences, 222, 9-18.

https://doi.org/10.1016/j.sbspro.2016.05.164

Society, T. N. A. (2015). Autism Friendly Design. Your Autism Magazine, 49(2), 513600-513600. Retrieved from http://www.autism.org.uk/professionals/others/architects/autism-friendly-design.aspx

The National Autistic Society. (2015). Autism-friendly design. The National Autistic Society, 49(2). Retrieved from http://www.autism.org.uk/professionals/others/architects/autism-friendly-design.aspx 